Accepted: 04/12/2020, Reviewed: 16/09/2021, Published: 31/01/2022

\title{
CRYSTALLINE AND DIGESTIVE CHARACTERISTICS OF HEAT MOISTURE TREATED AND ANNEALED LESSER YAM (Dioscorea esculenta) STARCH
}

\author{
Laksmi Putri Ayuningtyas*, Ashri Mukti Benita, Desy Triastuti \\ Food Technology Study Program, Faculty of Science and Technology, University of \\ Nahdlatul Ulama Purwokerto \\ Jl. Sultan Agung No. 42, Purwokerto 53144, Central Java \\ ${ }^{*}$ Correspondence author, Email: laksmiputria@gmail.com
}

\begin{abstract}
Hydrothermal modification is a physically safe modification applied in a food product to enhance its functional properties and to extend the starch application in the food industry. Heat Moisture Treatment (HMT) and Annealing (ANN) affect the starch's functional properties in its crystalline and digestive characteristics. Native starch is modified by HMT with $25 \%$ moisture content and 4 hours heating time, by ANN with starch and water ratio of $1: 3(\mathrm{w} / \mathrm{w})$, and 10 hours at $50^{\circ} \mathrm{C}$. Modified lesser yam starch by HMT and ANN have different crystalline and digestive characteristics from its native, although the modification do not change its granule morphology. The diffraction pattern of HMT starch is changed from A-type to A+B-type, but not on the ANN starch. Starch content and digestive value decreased, while amylose and resistant starch content increased compared to native starch. Hydrothermally modified starch could be considered as a raw material in thermally stable functional foods.
\end{abstract}

Keywords: Crystalline, Digestibility, Granules, Lesser yam, Starch

\section{INTRODUCTION}

Because of native starch from tubers has limited functional qualities, its applicability in food products is equally limited. Native starch from lesser yam has been widely used as the main ingredient in making pasta and bread. However, more than $30 \%$ usage of this ingredient reduces the overall acceptance of bread (Nindjin et al., 2011). Native starch can be modified chemically, physically and or enzymatically to expand its use in food products (Zhu, 2015). The physical modification of starch has gained a lot of attention lately because it has no byproducts such as those obtained from chemical modification. The biggest advantage of physical modification is that it is safe and uses natural ingredients. HMT (Heat Moisture Treatment) and ANN (Annealing) include as physical modification methods. HMT is categorized as a physical modification method that maintains water content at a level of less than $35 \%(\mathrm{w} / \mathrm{w})$ and is frequently given heating treatment for a certain period (Barua and Srivastav, 2017; Hoover, 2010). This is applied to samples with higher water content, commonly above $65 \%(\mathrm{w} / \mathrm{w})$ at a temperature below the gelatinization temperature and still below the glass transition temperature (Maache-Rezzoug et al., 2009; Tester and Debon, 2000).

The functional characteristics of native starch can be affected by hydrothermal modification of both HMT and ANN. In this case, HMT is able to increase gelatinization temperature, decrease granule development and amylose leaching, change the X-ray diffraction pattern, and increase or decrease the tendency to be enzymatically degraded (Zavareze and Dias, 2011). ANN is also reported to affect native starch in terms of starch molecules reorganization, increasing crystallinity, decreasing amylose leaching, granule development, acid hydrolysis tendency and increasing gelatinization temperature (Gomes et al., 2005; Vamadevan et al., 2013). Modified starch made from cassava, sweet potato, potato, mung beans, and arrowroot has a higher swelling power and a type $\mathrm{A}$ and $\mathrm{C}$ diffraction pattern, 
according to reports. Type A diffraction patterns are crystalline arrangements of amylopectin chains, whereas type C is a mixture pattern of types A and B. (Zhu, 2015). Beside its physicochemical properties, hydrothermal modification can also affect the digestibility rate of starch, which includes RDS (Rapidly Digestible Starch), SDS (Slowly Digestible Starch), and RS (Resistant Starch). RDS is glucose that is released after 20 minutes of incubation in enzymatic hydrolysis. Meanwhile, SDS is glucose which is released after 120 minutes of incubation, and RS is the remaining glucose after the incubation process (Englyst et al., 2018 ). RS has received much attention from food experts and producers since it is a type of starch that is not degraded in the small bowel so that it can be fermented by good bacteria in the colon to produce metabolites that can prevent colon cancer and provide other health benefits to consumers (Chung et al., 2009).

HMT and ANN trigger changes in the structure and properties of native starch differently depending on several factors including starch source, amylose and amylopectin composition and treatment conditions (temperature, time and water content used) (Zavareze and Dias, 2011). Hydrothermally modified starch is suggested to be applied in making noodles and bakery products (Mathobo et al., 2020). This is because hydrothermal modification can increase the stability of starch to heat and reduce the tendency for retrogradation. Therefore, this method is suitable to be applied in food products that require stability against heat. This study aims to figure out the effect of hydrothermal modification of HMT and ANN on the crystallinity and digestibility characteristics of lesser yam starch.

\section{METHODOLOGY}

\section{Materials}

Fresh lesser yam was obtained from the Banyumas area, Central Java, with a harvest time of 6-9 months. The supporting materials used were distilled water, $\mathrm{Na}_{2} \mathrm{~S}_{2} \mathrm{O}_{5}$ and deionized water. Any chemicals used for analysis were $5 \%$ phenol solution, concentrated $\mathrm{H}_{2} \mathrm{SO}_{4}$, iodine solution, $1 \mathrm{~N} \mathrm{NaOH}, 95 \%$ ethanol, $1 \mathrm{~N}$ acetic acid, $\mathrm{pH} 7$ phosphate buffer, DNS solution, $\mathrm{pH}$ $1.5 \mathrm{HCl}$ buffer, pepsin solution, tris-maleate buffer, $\alpha$-amylase enzyme solution, $4 \mathrm{M} \mathrm{KOH}, 2$ $\mathrm{M} \mathrm{HCl}, 4 \mathrm{M}$ sodium acetate buffer, amyloglucosidase enzyme and GOPOD reagent.

\section{Tools}

Scale, knife, filter cloth, blender, 60 and 100 mesh sieve, refrigerator, oven, cabinet dryer, X-Ray Diffractometer (XRD), spectrophotometer, Scanning Electron Microscope (SEM), measuring flask, test tube, vortex, water-bath, Erlenmeyer flask, aluminum foil, centrifuge, measuring pipette and micropipette.

\section{Research Design}

The experimental design used in this study was a non-factorial Completely Randomized Design (CRD). All samples were analyzed three times and given a standard deviation except for the results of $\mathrm{X}$-ray diffraction analysis and granule morphology.

\section{Method}

Extraction of Lesser Yam Starch (Pokatong et al., 2014)

0.02 percent $(\mathrm{w} / \mathrm{v}) \mathrm{Na}_{2} \mathrm{~S}_{2} \mathrm{O}_{5}$ solution was used to extract lesser yam starch. Initially, the lesser yam was peeled off to remove the outer shell, the defective or damaged part was removed, and then cut into approximately sized cubed $3 \times 3 \times 3 \mathrm{~cm}$. Then, the lesser yam was weighed as many as $1000 \mathrm{~g}$ before immersed in $4 \mathrm{~L}$ of $0.02 \%(\mathrm{w} / \mathrm{v}) \mathrm{Na}_{2} \mathrm{~S}_{2} \mathrm{O}_{5}$ solution with a 1:4 (lesser yam: $\mathrm{Na}_{2} \mathrm{~S}_{2} \mathrm{O}_{5}$ ) ratio for 10 minutes. After that, the lesser yam was crushed for 2 minutes using a blender. Filter cloth was used in the separation process so that the solids and the filtrate were separated to obtain suspended starch. The suspended starch was put in the refrigerator (at 4-5oC) for 5 hours for the deposition process followed by demineralized water rinsing process (twice) to remove any remaining solvent. The solids were then dried in an oven 
(at $500 \mathrm{C}$ ) for 18 hours before being ground dry with blender to produce a fine powder. Lesser yam starch powder was prepared by sifting the fine powder through a 60 mesh sieve.

Heat Moisture Treatment Starch Modification Process (Collado et al., 2001)

Before applying heating treatment in the HMT method, the water content of lesser yam starch was firstly set by spraying it with distilled water and stirring it until $25 \%$ of moisture content reached. The starch was refrigerated during incubation for 12 hours at $100 \mathrm{C}$ and then thawed. The starch was then aluminum foil tightly packed and heated for 4 hours in an oven at $110 \mathrm{oC}$. The starch then dried to obtain $10-12 \%$ of water content using a cabinet dryer at a temperature of $50 \mathrm{oC}$. To get fine powder, it was pounded with a grinder and sieved through a 100 mesh sieve.

Annealing Starch Modification Process (Pinto et al., 2015)

To initiate the ANN method, $100 \mathrm{~g}$ of lesser yam starch was suspended in deionized water at a starch:deionized water mixture of 1:3 (w/w). After that, it was filled in an alumunium foiled erlenmeyer before incubated in an oven at the temperature of $50 \mathrm{oC}$ for 10 hours. After being incubated, filter paper was used to filter the starch suspension. The suspension was washed twice with water, followed by overnight oven-dried at $40 \circ \mathrm{C}$. The dried suspension was then mashed for further analysis.

\section{Data Analysis}

Variance analysis was performed on the data obtained by using SPSS 16 . The DMRT (Duncan's Multiple Range Test) was used to confirm the existence of a significant variation at the $5 \%$ significance value.

\section{Research Stages}

The research was divided into three stages. The first stage of the research was the starch extraction from the lesser yams in accordance with Pokatong et al., (2014). The second stage was modification of lesser yam starch with Heat Moisture Treatment based on Collado et al., 2001, and the modification of annealing was carried out based on Pinto et al., 2015. The third stage is the analysis of the physicochemical properties of starch. Native starch and modified starch were analyzed for several physicochemical properties of starch, including Xray diffraction analysis (Todica et al., 2016), analysis of starch granule morphology (Lawal et al., 2005), analysis of total starch content, amylose content, digestability (Faridah et al., 2013), and analysis of resistant starch (Kumari et al., 2007).

\section{RESULTS AND DISCUSSION}

\section{X-Ray Diffractogram of Native Starch and Modified Starch}

The starch of tubers is known to have a crystalline type, namely type $B$ with peaks found at 5.5-5.6 $6^{\circ}, 14.1^{\circ}, 15.0^{\circ}, 17.0^{\circ}, 19.7^{\circ}, 22.2^{\circ}$ and $24^{\circ}$ at an angle of $2 \theta$ (Buléon et al., 1987). Based on the research of Jayakody et al. (2007), three varieties of lesser yam (Dioscorea esculenta) were examined, and all had a type B crystalline pattern. This is consistent with this study, where the peaks were found at $5.63^{\circ}, 15.05^{\circ}, 17.04^{\circ}, 19.71^{\circ}$ and $24.39^{\circ}$ at $2 \theta$ angles for native starch, and this pattern is a type $B$ crystalline pattern.

The HMT treatment has caused the crystallinity characteristic of native starch to change. The peaks found in HMT starch were at $15.07^{\circ}, 17.09^{\circ}, 17.78^{\circ}, 22.94^{\circ}$ at an angle of $2 \theta$. It can be seen in Figures $1 \mathrm{a}$ and $1 \mathrm{~b}$ that compared to native starch, the peak intensity of HMT starch decreased. The crystalline pattern of the HMT starch examined was similar to the type A crystalline pattern. The type A crystalline pattern was characterized by a distinctive peak at $2 \theta=15.3,17.0,18.0$, and $23^{\circ}$ (Buléon et al, 1987 ). HMT treatment was reported to have the ability to change the crystalline type of starch from type B to A (Vermeylen et al., 2006, Sui et al., 2015) or have a mixed type A + B (Gunaratne et al., 2002). The modified HMT treatment made the starch peak shifted. After HMT, the peak that typical for B-type peak such as $5,6^{\circ}$ 
disappeared, and peak at $17^{\circ}$ split into double peaks at $17^{\circ}$ and $18^{\circ}$ that typical for A-type. The $17.089^{\circ}$ peak found in native starch and ANN starch, for HMT starch the peak was found at $17.039^{\circ}$ at an angle of $2 \theta$. The type A crystalline pattern has the characteristics of a dense structure to prevent chemical reactions, in this case, is hydrolysis (Dome et al., 2020). ANN starch has its peaks at $5.66^{\circ}, 10.05^{\circ}, 14.26^{\circ}, 14.69^{\circ}, 15.09^{\circ}, 16.42^{\circ}, 17.13^{\circ}, 19.79^{\circ}, 22.15^{\circ}$, $24.51^{\circ}$ at an angle of $2 \theta$, which is a type B crystalline pattern (Figure 1c). According to Vermeylen et al. (2006), annealing modification does not affect the crystalline type of starch. The peak position does not change and the crystallinity has decreased.

a.
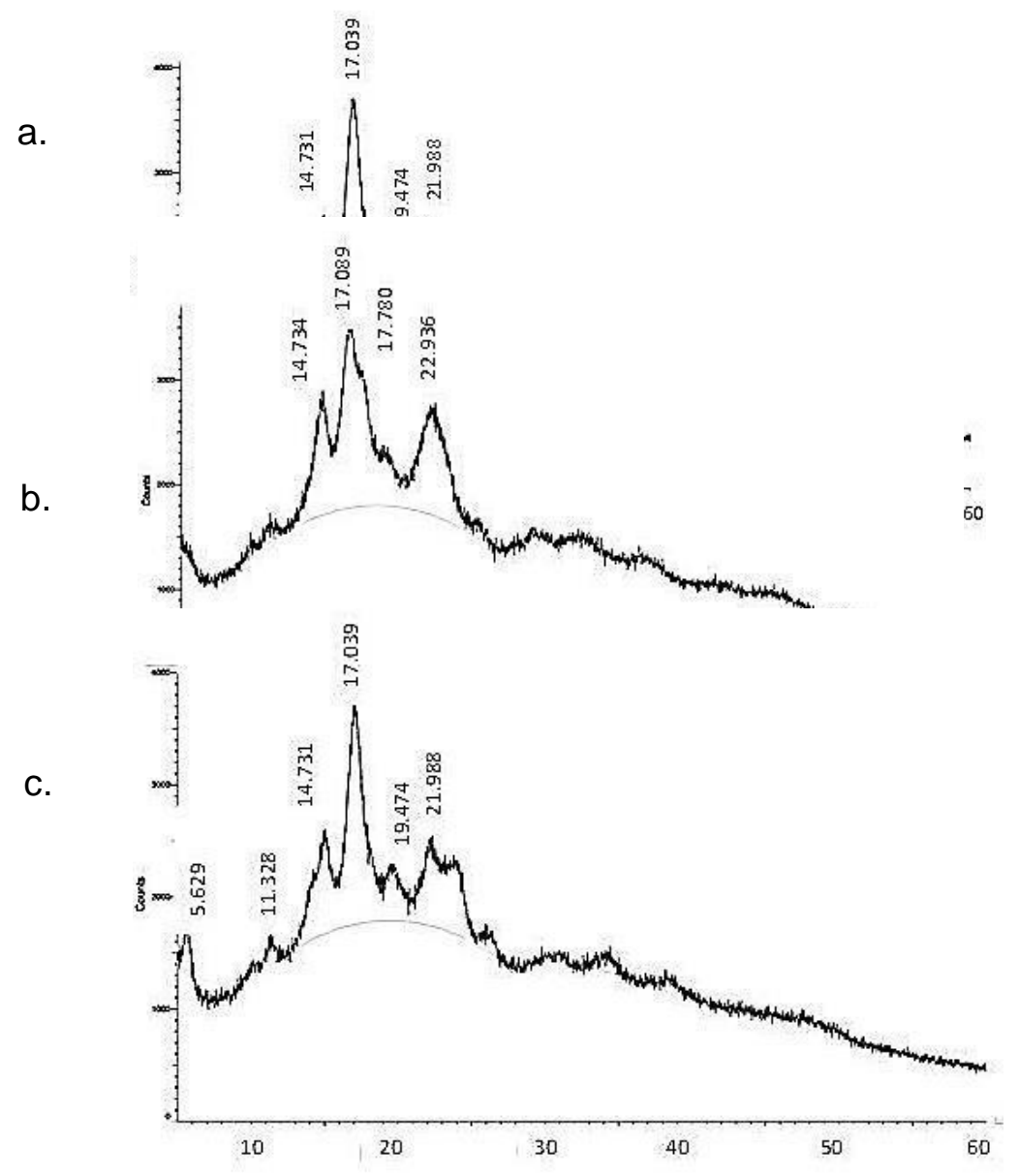

Figure 1. The Diffractogram Pattern (XRD) of Native Starch (a), HMT-Modified Starch (b) and ANN-Modified Starch (c).

\section{Starch Granule Morphology}

Based on Jiang et al., (2012), lesser yam starch granules (Dioscorea esculenta) have a polygonal shape with a smooth surface. The SEM results in Figure 2 show that the lesser yam starch examined with a magnification of $5000 x$, the starch granules of either native starch or hydrothermally modified starch still have the same shape, namely polygonal. It means that hydrothermal modification treatment does not change the shape of the native starch granules. Farias et al, (2019) stated that hydrothermal modification treatment does not result in changes in starch granule morphology. The size of the starch granules examined was around 3-5 $\mu \mathrm{m}$ for the three types of starch. This condition is not affected by the type of hydrothermal modification used. Nattapulwat et al. (2009) mentioned that lesser yam starch granules also have a polygonal shape and range in size from 2-20 $\mu \mathrm{m}$. Meanwhile, Rugchati et al. (2010) reported that the granule size of lesser yam starch grown in Thailand was $4.75 \mu \mathrm{m}$. 


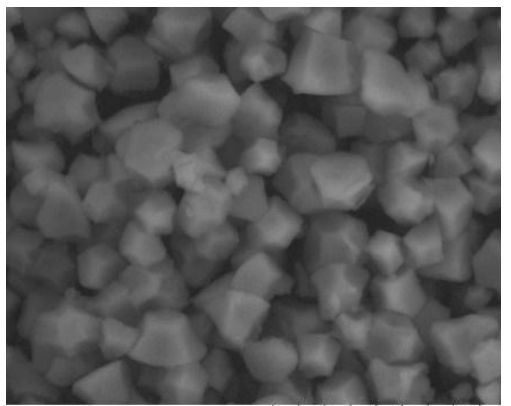

a. Native starch

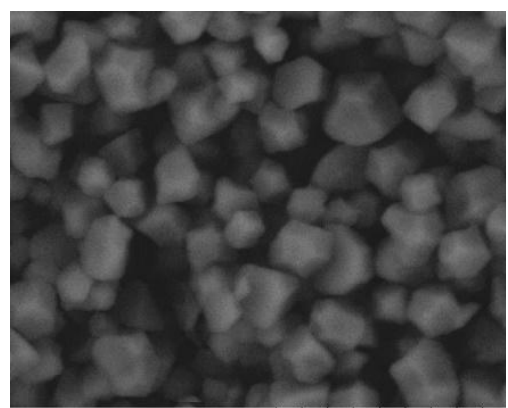

b. HMT Starch

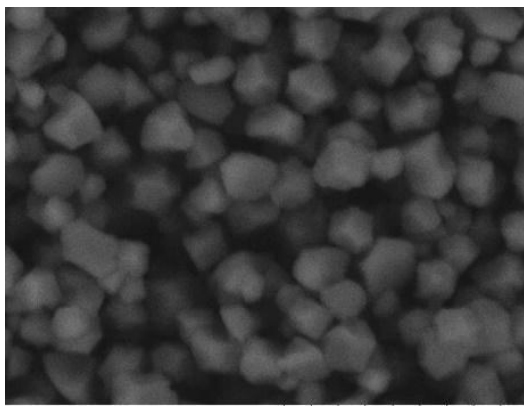

c. ANN Starch

Figure 2. Scanning Electron Microscope (SEM) Morphology of Native Starch Granules (a), HMT starch (b) and ANN starch (c) with an Enlargement of 5000x

\section{Content of Starch and Amylose}

The content of hydrothermally modified starch both HMT and ANN decreased compared to native starch. The content of native starch, HMT, and ANN was $89.31 \%, 84.22 \%$ and $82.63 \%$, respectively (Table 1). Along with the decreasing starch content, amylose content increased significantly compared to native starch. Amylose concentration of lesser yam starch varies between genotypes Dioscorea and ranges from 15.1 to 27.1 percent (Otegbayo et al., 2014). D. esculenta has a considerably lower amylose content in its native starch compared to the other genotypes, which is less than $20 \%$ compared to other species in the Dioscorea family, such as $D$. rotundata, $D$. alata, $D$. cayenensis, and $D$. cayenensis-rotundata (Otegbayo et al., 2014). The amylose content of lesser yam starch in this study was lower than that of Riley et al. (2004) which reached $11.1 \%$. The amylose content in native starch is also influenced by some factors such as environmental factors and agronomic practices, as well as the harvest age (Alcázar-Alay and Meireles, 2015). Hydrothermal modification treatment both HMT and ANN significantly increased amylose content compared to native starch (Table 1). Higher amylose content of HMT and ANN starch apparently affected by the temperature and moisture content used in this treatment compared to native starch. The higher temperature could lead to amylopectin molecule degradation, resulting in linear double helix shorter chains that counted as amylose.

Table 1. Starch and Amylose Content of Native Starch and Hydrothermal Modified Starch

\begin{tabular}{lcc}
\hline Samples & Starch (\%) & \multicolumn{1}{c}{ Amylose (\%) } \\
\hline Native & $89.31 \pm 0.11 \mathrm{c}$ & $4.13 \pm 0.009 \mathrm{a}$ \\
HMT & $84.22 \pm 0.11 \mathrm{~b}$ & $4.37 \pm 0.018 \mathrm{c}$ \\
ANN & $82.63 \pm 0.33 \mathrm{a}$ & $4.31 \pm 0.09 \mathrm{~b}$ \\
\hline
\end{tabular}

\section{Starch Digestibility}

The digestibility value of hydrothermally modified starch, both HMT and ANN, decreased significantly in digestibility compared to native starch (Figure 2). Gunaratne and Hoover, (2002) reported that the modification of the HMT on $D$. alata is hydrolyzed to a slightly extent than native starch. The resistance of HMT-modified starch to hydrolysis indicated a strong amylose chain interaction formed during the HMT process. As previously explained, HMT in lesser yam starch changes the crystallinity type of starch from $B$ to type $A+B$, where type $A$ is a crystallinity type with more resistance to acid and enzyme hydrolysis because of more compact and closed granule structure (Wang et al., 2009). This was also confirmed by the data that the percentage of RS content of HMT starch was the highest compared to ANN modified starch and its native starch (Figure 3 ). Hydrogen bonds can be formed during HMT which leads to the formation of a more compact starch structure and a decrease in the distance between granules (Barua and Srivastav, 2017). 


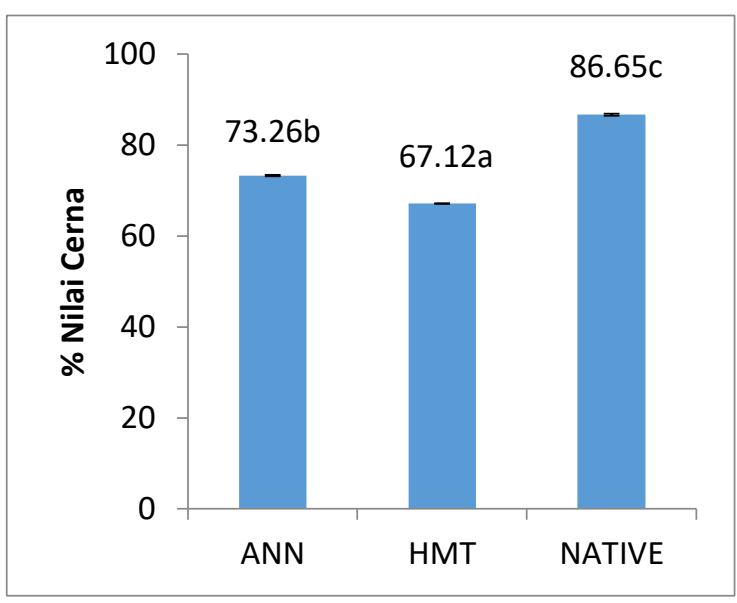

a.

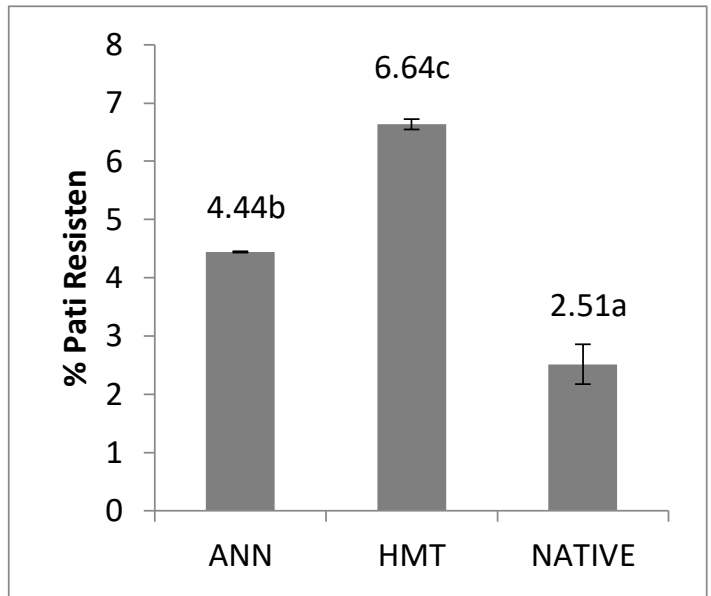

b.

Figure 3. Digestibility Value (a) and RS Content (b) of Native Starch and Hydrothermal Modified Starch

It can be seen in Figure 2a that the ANN modified starch had a significantly lower digestibility value than the native starch. However, it was still higher than the HMT starch. The development of compact crystallites and the association among both amylose-amylose and/or amylose-amylopectin contribute to the increase in resistance to enzyme hydrolysis in ANN starch (Rocha et al., 2010). Vamadevan et al. (2013) reported that ANN starch of lesser yam had the highest $\Delta \mathrm{H}$ value compared to other starches. This is because there is a change in the chemical structure of starch, where the inter-block chain length (IB-CL) of the amylopectin fraction of lesser yam starch experiences an elongation, triggering the formation of a compact structure of amylose double helix and crystalline granules, which causes a more organized and very neatly arranged structure. This was also indicated by the RS content of ANN starch, which was indeed higher than native starch, but still lower than HMT (Figure 2b). Similar results were shown by Chung et al. (2009) where HMT starch had the highest RS content compared to native starch and ANN starch for peas, lentils and corn.

\section{CONCLUSIONS}

Hydrothermal modification in the form of HMT and ANN can change the characteristics of native starch of lesser yam. The HMT starch X-ray diffraction pattern shifted from type $A$ to $A+B$, while ANN starch did not change compared to native starch. It also did not damage the starch granule morphology. The hydrothermally modified starch content was reduced with an increased amount of starch amylose fraction compared to native starch. In terms of digestibility, HMT and ANN starch has lower digestibility and higher content of resistant starch than native starch. This is due to the formation of a more compact chemical structure of starch. Based on this result, hydrothermally modified starch is highly advised to be used as a functional food since it has lower digestibility, making it suitable for diabetics, and has the potential as a prebiotic.

\section{ACKNOWLEDGMENT}

The author would like to express warm gratitude to DRPM DIKTI who has provided research funding through the Beginner Lecturer Research scheme for the year 2020. 


\section{REFERENCES}

Alcázar-Alay, S. C., \& Meireles, M. A. A. (2015). Physicochemical properties, modifications and applications of starches from different botanical sources. Food Science and Technology, 35(2), 215-236.

Barua, S., and Srivastav, P.P. (2017). Effect of Heat-Moisture Treatment on Resistant Starch Functional and Thermal Properties of Mung Bean (Vigna radiate) Starch. Journal of Nutritional Health \& Food Engineering, 7(4), 358-363.

Buléon, A., Bizot, H., Madeleine Delage, M., \& Pontoire, B. (1987). Comparison of X-ray diffraction patterns and sorption properties of the hydrolyzed starches of potato, wrinkled and smooth pea, broad bean and wheat. Carbohydrate Polymers, 7(6), 461482.

Chung, H. J., Liu, Q., \& Hoover, R. (2009). Impact of annealing and heat-moisture treatment on rapidly digestible, slowly digestible and resistant starch levels in native and gelatinized corn, pea and lentil starches. Carbohydrate Polymers, 75(3), 436-447.

Collado, L. S., Mabesa, L. B., Oates, C. G., \& Corke, H. (2001). Bihon-type noodles from heatmoisture-treated sweet potato starch. Journal of Food Science, 66(4), 604-609.

Dome, K., Podgorbunskikh, E., Bychkov, A., \& Lomovsky, O. (2020). Changes in the crystallinity degree of starch having different types of crystal structure after mechanical pretreatment. Polymers, 12(3), 1-12.

Englyst, K., Goux, A., Meynier, A., Quigley, M., Englyst, H., Brack, O., \& Vinoy, S. (2018). Inter-laboratory validation of the starch digestibility method for determination of rapidly digestible and slowly digestible starch. Food Chemistry, 245(August 2017), 11831189.

Farias, F. O., Granza, A. G., Travalini, A. P., de Oliveira, C. S., Schnitzler, E., \& Demiate, I. M. (2019). Evaluation of the effects of single and dual hydrothermal treatments on the properties of Carioca bean (Phaseolus vulgaris L.) starch. International Food Research Journal, 26(1), 337-344.

Faridah, D. N., Rahayu, W. P., Faridah, D. N., \& Rahayu, W. P. (2013). modifikasi pati garut (marantha arundinacea) dengan perlakuan hidrolisis asam dan siklus pemanasanpendinginan untuk menghasilkan pati resisten tipe 3. Jurnal Teknologi Industri Pertanian, 23(1), 61-69.

Gomes, A. M. M., Mendes Da Silva, C. E., \& Ricardo, N. M. P. S. (2005). Effects of annealing on the physicochemical properties of fermented cassava starch (polvilho azedo). Carbohydrate Polymers, 60(1), 1-6.

Gunaratne, A., \& Hoover, R. (2002). Effect of heat-moisture treatment on the structure and physicochemical properties of tuber and root starches. Carbohydrate Polymers, 49(4), 425-437.

Hoover, R. (2010). The impact of heat-moisture treatment on molecular structures and properties of starches isolated from different botanical sources. Critical Reviews in Food Science and Nutrition, 50(9), 835-847.

Jayakody, L., Hoover, R., Liu, Q., \& Donner, E. (2007). Studies on tuber starches. II. Molecular structure, composition and physicochemical properties of yam (Dioscorea $\mathrm{sp}$.) starches grown in Sri Lanka. Carbohydrate Polymers, 69(1), 148-163.

Jiang, Q., Gao, W., Li, X., Xia, Y., Wang, H., Wu, S., ... Xiao, P. (2012). Characterizations of starches isolated from five different Dioscorea L. species. Food Hydrocolloids, 29(1), $35-41$.

Kumari, M., Urooj, A., and Prasad, N. N. (2007). Effect of storage on resistant starch and amylose content of cereal-paste based ready-to-eat commercial product. Food chem. 102: 1425-1430.

Lawal, O. S. (2005). Studies on the hydrothermal modifications of new cocoyam (Xanthosoma sagittifolium) starch. International Journal of Biological Macromolecules, 37(5), 268277. 
Maache-Rezzoug, Z., Maugard, T., Zarguili, I., Bezzine, E., El Marzouki, M. N., \& Loisel, C. (2009). Effect of instantaneous controlled pressure drop (DIC) on physicochemical properties of wheat, waxy and standard maize starches. Journal of Cereal Science, 49(3), 346-353.

Mathobo, V. M., Silungwe, H., Ramashia, S. E., \& Anyasi, T. A. (2020). Effects of heatmoisture treatment on the thermal, functional properties and composition of cereal, legume and tuber starches-a review. Journal of Food Science and Technology.

Nattapulwat, N., Purkkao, N., \& Suwithayapan, O. (2009). Preparation and application of carboxymethyl Yam (Dioscorea esculenta) Starch. AAPS PharmSciTech, 10(1), 193198.

Nindjin, C., Amani, G. N., \& Sindic, M. (2011). Effect of blend levels on composite wheat doughs performance made from yam and cassava native starches and bread quality. Carbohydrate Polymers, 86(4), 1637-1645.

Otegbayo, B., Oguniyan, D., \& Akinwumi, O. (2014). Physicochemical and functional characterization of yam starch for potential industrial applications. Starch/Staerke, 66(3-4), 235-250.

Pinto, V. Z., Vanier, N. L., Deon, V. G., Moomand, K., El Halal, S. L. M., Zavareze, E. D. R., ... Dias, A. R. G. (2015). Effects of single and dual physical modifications on pinhão starch. Food Chemistry, 187, 98-105.

Pokatong, W. D. R., C. Lestari, dan T. S. Mastuti. 2014. Pemanfaatan Pati Gembili (Dioscorea esculenta lour. Burkill) dengan Penambahan Plasticizer sebagai Edible Coating pada Stroberi (Fragaria ananassa). Prosiding SNST ke-5 Tahun 2014 Fakultas Teknik Universitas Wahid Hasyim Semarang.

Riley, C. K., Wheatley, A. O., Hassan, I., Ahmad, M. H., Morrison, E. Y. S. A., \& Asemota, H. N. (2004). In vitro Digestibility of Raw Starches Extracted from five Yam (Dioscorea spp.) Species Grown in Jamaica. Starch/Staerke, 56(2), 69-73.

Rocha, T. de S., Carneiro, A. P. de A., \& Franco, C. M. L. (2010). Effect of enzymatic hydrolysis on some physicochemical properties of root and tuber granular starches. Ciência $e$ Tecnologia de Alimentos, 30(2), 544-551.

Rugchati, O. (2010). Comparison in some characteristics of yam tubers starch (Dioscoreaceae spp.) from Thailand. International Journal of Environmental and Rural Development, 1(2), 102-106.

Sui, Z., Yao, T., Zhao, Y., Ye, X., Kong, X., \& Ai, L. (2015). Effects of heat-moisture treatment reaction conditions on the physicochemical and structural properties of maize starch: Moisture and length of heating. Food Chemistry, 173, 1125-1132.

Tester, R. F., \& Debon, S. J. J. (2000). Annealing of starch - A review. International Journal of Biological Macromolecules, 27(1), 1-12.

Todica, M., Nagy, E. M., Niculaescu, C., Stan, O., Cioica, N., \& Pop, C. V. (2016). XRD investigation of some thermal degraded starch based materials. Journal of Spectroscopy, 2016.

Vamadevan, V., Bertoft, E., Soldatov, D. V., \& Seetharaman, K. (2013). Impact on molecular organization of amylopectin in starch granules upon annealing. Carbohydrate Polymers, 98(1), 1045-1055.

Vermeylen, R., Goderis, B., \& Delcour, J. A. (2006). An X-ray study of hydrothermally treated potato starch. Carbohydrate Polymers, 64(2), 364-375.

Zavareze, E. D. R., \& Dias, A. R. G. (2011). Impact of heat-moisture treatment and annealing in starches: A review. Carbohydrate Polymers, 83(2), 317-328.

Zhu, F. (2015). Isolation, Composition, Structure, Properties, Modifications, and Uses of Yam Starch. Comprehensive Reviews in Food Science and Food Safety, 14(4), 357-386. 